\title{
On the genetics of sleep disorders: genome-wide association studies and beyond
}

\author{
This article was published in the following Dove Press journal: \\ Advances in Genomics and Genetics \\ 13 August 2015 \\ Number of times this article has been viewed
}

\section{Michael J Parsons}

Mammalian Genetics Unit, MRC Harwell, Harwell, Oxfordshire, UK
Correspondence: Michael J Parsons Mammalian Genetics Unit, MRC Harwell, Harwell Science and Innovation Campus, Oxfordshire, OXII ORD, UK

Tel +44 I2 3584 I484

Emailm.parsons@har.mrc.ac.uk

\begin{abstract}
Sleep is an essential behavior, yet much of its underlying functions are still unknown. The disruption of sleep can led to a variety of health consequences. Family and twin studies have together shown that genetic factors underlie variation in sleep characteristics and sleep disorders. Given the importance of sleep to our well-being, understanding its underlying genetic factors is essential to both the prevention and treatment of these disorders. Recently, genome-wide association studies (GWAS) have helped to provide evidence of associations of both known and novel genetic variants with sleep disorders. This review outlines the findings from GWAS for a number of sleep disorders, including insomnia, restless leg syndrome, obstructive sleep apnea, and narcolepsy, and discusses these findings in the context of supporting evidence from independent methodologies. Finally, the limitations of GWAS approaches are outlined, along with the future directions of the genetics of sleep in the post-GWAS era.
\end{abstract}

Keywords: genome-wide association studies, sleep, sleep disorder, insomnia, restless leg syndrome, obstructive sleep apnea, narcolepsy

\section{Introduction}

Sleep is a fundamental state in which we spend approximately one-third of our lives. Our dedication to this activity likely reflects its profound significance in many areas of our functioning and well-being, and the consequences of its disruption can be profound. Sleep disorders are common, and range from: disturbances of sleep duration and quality, such as insomnia; sleep-related movement disorders, such as restless leg syndrome (RLS); breathing difficulties during sleep, such as obstructive sleep apnea (OSA); and the dissociation between sleeping and waking states, such as narcolepsy. Given the importance of sleep to our well-being, understanding the genetic and environmental factors that underlie individual differences with regard to sleep and sleep disorders is essential to put us in a stronger position to prevent and treat these disorders.

Traditional "family studies" investigate whether a particular trait runs in families, thus providing a starting point to determine the extent of genetic influences underlying specific sleep phenotypes and sleep disorders. Family studies have highlighted a genetic component in a number of sleep disorders, including insomnia, ${ }^{1-3} \mathrm{RLS},{ }^{4} \mathrm{OSA},{ }^{5}$ and narcolepsy. ${ }^{6}$ Twin studies have also detected a genetic component for a range of sleep phenotypes, including sleep duration, insomnia, RLS, OSA, and narcolepsy. ${ }^{7}$

A variety of approaches have been used to identify genes underlying the heritability of sleep and sleep disorders, including the use of animal models and candidate gene association studies in human cohorts. Candidate gene association studies for sleep and sleep disorders using human genetic cohorts have identified a number of 
potential loci; however, they are limited because they focus on known or suspected candidate genes for a disorder. ${ }^{8}$ Animal models have implicated various molecular pathways involved in sleep, including neurotransmitter systems (adenosine, histamine, dopamine, acetylcholine, norepinephrine, gamma-aminobutyric acid, and serotonin), ion channels, genes associated with immune function, intracellular messengers, and genes involved in regulating circadian rhythms. ${ }^{89}$ Traditionally, mammalian models (eg, mice, rats, and dogs) were used, although recently simpler model systems have been adopted (eg, drosophila, Caenorhabditis elegans, and zebra fish). Choice of the model used is often balanced between a number of factors, including the ease of fine genetic manipulation, similarity in sleep architecture to humans, and the resources required for maintaining these models.

More recently, researchers are turning to unbiased approaches to find genetic variants in novel genes implicated in these disorders, such as genome-wide association studies (GWAS). ${ }^{10}$ By comparing the genome-wide genetic variation across individuals, usually using case and control groups, GWAS provide powerful evidence to support the role of a genetic variant in a disorder. GWAS range in both sample size and number of single nucleotide polymorphisms (SNPs) investigated, with the trend being for larger sample sizes, (thousands if not tens of thousands) and a greater coverage of SNPs (typically $300-500,000^{+}$SNPs). GWAS have provided evidence for the involvement of numerous, often novel, genes underlying a range of sleep disorders. The purpose of this review is to summarize these findings, discuss their implications for sleep research, and outline the future directions of the genetics of sleep in the post-GWAS era.

\section{GWAS for sleep duration}

Sleep duration varies widely among individuals and has been associated with numerous health outcomes. Twin studies have shown that self-reported sleep duration has a heritability ranging from $31 \%$ to $37 \% .{ }^{11,12}$ Candidate gene association studies for sleep duration have nominated a number of potential loci, although many have not been replicated. Strong/ substantial evidence has been found for an association of sleep duration with polymorphisms in the CLOCK gene ${ }^{13-15}$ and in a functional variant of the circadian gene $D E C 2 .{ }^{16,17}$

In the first GWAS that focused on sleep duration and usual bedtime using a self-reported questionnaire, the authors genotyped over 70,000 SNPs in approximately 750 individuals and found five suggestive peaks (logarithm of odds $(>2)$; four associated with usual bedtime and one with sleep duration. ${ }^{18}$ These linkage peaks contained a number of genes, including the circadian genes Casein kinase II subunit alpha 2 (CSNK2A2), a known component of the core circadian clock, and Prokineticin2 (PROK2), a neuropeptide that is important in circadian signaling. ${ }^{19}$ The most significant association with sleep duration was a SNP within the intron of cyclic adenosine monophosphate-specific $3^{\prime}, 5^{\prime}$-cyclic phosphodiesterase 4D (PDE4D) (rs 1823068, $P=2.5 \mathrm{e}-8)$, a gene that is expressed throughout the brain (see Table 1 for a summary of all genome-wide significant loci). A nonsynonymous SNP in neuropeptide S receptor 1 (NPSR1; rs324981, $P=1.8 \mathrm{e}-5$ ) was associated with a delayed bedtime of 15 minutes per Ile107 allele.

A second GWAS investigated sleep duration using the Munich Chronotype Questionnaire in a large European sample $(\mathrm{n}=4,251) .{ }^{20}$ This study found an association between an intronic variant ( $\mathrm{rs} 11046205, P=4.0 \mathrm{e}-8)$ in the adenosine triphosphate-binding cassette, sub-family $\mathrm{C}$ member 9 $(A B C C 9)$ gene (an adenosine triphosphate-sensitive potassium channel) and sleep duration. This SNP explained 5\% of the variation in sleep duration, such that having at least one $\mathrm{G}$ allele was associated with a decrease in sleep duration of approximately 30 minutes. Although not replicated in the overall sample of an independent cohort, there was a significant association in a subsample limited to morning chronotypes collected during the winter (both chronotype and seasonality independently affect sleep duration). There was significant replication in an independent sample of rs11046205 and sleep duration $(P<0.05)$, but sleep duration was only lower in those individuals with two copies of the G allele. ${ }^{21}$ Neuronal-specific knockdown of the drosophila homolog (Sur2) resulted in an almost complete loss of sleep during the first 3 hours of the night. ${ }^{20}$

Another GWAS investigating sleep duration in a Finnish population $(n=1,941)$ failed to find any genome-wide signals, although it did find 31 SNPs with a lower statistical cut-off $(P<5$ e-5). Three of these SNPs were nominally associated with sleep duration in a replication sample $(n=6,834)$ : rs10914351 near receptor-type tyrosine-protein phosphatase PCP-2 ( $P=0.049)$, rs1037079 in protocadherin-7-CENTD1 $(P=0.011)$, and rs2031573 in Krueppel-like factor 6 (KLF6), a transcription factor $(P=0.044) .{ }^{22}$ Interestingly, both the rs2031573 and rs1037079 SNPs were associated with decreased KLF6 mRNA expression in blood $(P<0.05)$, suggesting that these SNPs may have functional consequences. As single-gene analysis misses the effects of a set of genes on a shared biological pathway, many researchers additionally investigate whether there is enrichment of specific gene ontology (GO) terms for a given gene list. Such a pathway 
enrichment analysis using nominally significant associations found enrichment of the mitogen-activated protein kinase signaling pathway (including $C A C N A 1 C$ ), $\mathrm{ABC}$ transporters (including $A B C C 9$ ), and long-term depression $(P<0.05) .{ }^{22}$ However, this study failed to replicate the previous associations of $A B C C 9(\mathrm{rs} 11046205)^{20}$ or PDE4D (rs1823068) $)^{18}$ with sleep duration.

Finally, a recent GWAS investigating sleep duration in a large European sample $(n=47,180)$ found two novel genomewide significant (GWS) loci, one on chromosome 2 , in an intergenic region (rs1 191685, $P=1.1 \mathrm{e}-9$ ) upstream of Paired box gene $8(P A X 8)$, a thyroid specific transcription factor, and another on chromosome 6 , in an intergenic region (rs4587207, $P=2.0 \mathrm{e}-8)$ upstream of radiation-inducible immediate-early gene IEX-1 (IER3), flotillin-1 (FLOT1), and a non-coding RNA (LINC00243). ${ }^{23}$ The association of the chromosome 2 loci SNPs with sleep duration were successfully replicated, whereas the chromosome 6 loci SNPs were not. This study failed to find any associations with core circadian genes and failed to replicate the previous association of the $A B C C 9$ gene with sleep duration. ${ }^{20}$

No single genome-wide association for sleep duration has been consistently replicated across these studies. The inconsistencies are likely due to, among other things, the use of a wide range of self-reported questionnaires to access sleep duration. Measures of sleep assessed using questionnaires do not always marry up well with measures assessed in other ways, such as actigraphy or electroencephalographic recordings. ${ }^{24}$ Furthermore, while one third of self-reported sleep duration is heritable, sleep power measured using electroencephalography has a heritability estimated to be as high as $95 \%,{ }^{25}$ and may be better suited to detect genetic variation associated with sleep characteristics. Future GWAS for sleep duration would be aided by the use of a more consistent and biologically relevant assessment of sleep duration.

\section{GWAS for insomnia and sleep quality}

Insomnia is a sleep disorder characterized by the inability to fall asleep or maintain sleep (for more comprehensive criteria, see the Diagnostic and Statistical Manual of Mental Disorders, Fifth Edition $\left.{ }^{26}\right)$. It is one of the most common sleep disorders, affecting as many as $10 \%-15 \%$ of the adult population, although the prevalence depends on the definition of insomnia used. ${ }^{27}$ Although a large twin study found that genetic heritability for insomnia was estimated at $57 \%,{ }^{28}$ little is known about the underlying genetic variation, which is likely due to inconsistencies in defining insomnia. ${ }^{29}$ Candidate gene studies for insomnia have nominated genetic variants within the circadian gene $C L O C K,{ }^{30}$ the GABAergic system, ${ }^{31}$ the adenosinergic system, ${ }^{32}$ and the serotonergic system. ${ }^{33,34}$

The first GWAS for insomnia investigated just over 81,000 SNPs in a Korean population $(n=8,842) .{ }^{35}$ The strongest association was found for a SNP within the receptor tyrosine kinase-like orphan receptor 1 (ROR1) gene (rs11208305, $P<5$.6e-6), which is involved in synaptic formation. ${ }^{36}$ Interestingly, GO term analysis of genes nominally associated with insomnia found an enrichment for neuronal function $(P<0.05)$. The next most significant association was for a SNP within 1-phosphatidylinositol-4,5-bisphosphate phosphodiesterase beta-1 (PLCB1; rs7187712, $P<8.5 \mathrm{e}-6$ ), one of 16 SNPs in this gene nominally associated with insomnia. $P L C B 1$ was one of many genes that were nominally associated with insomnia that are also known to function in learning and memory-related calcium signaling.

A GWAS that investigated self-reported sleep habits in an Australian sample $(n=2,323)$ assessing more than 2,000,000 SNPs failed to find any GWS hits; however, it did find a group of seven SNPs in perfect linkage disequilibrium within the third intron of $C A C N A 1 C$, a gene that encodes the $1 \mathrm{C}$ subunit of a l-type voltage-gated calcium channel, that were strongly associated with sleep latency (the most significant SNP being rs7304986, $P=1.3 \mathrm{e}-6)$ and another $C A C N A 1 C$ variant (rs7304986) associated with sleep quality $(P=4.4 \mathrm{e}-6) \cdot{ }^{37}$ Another SNP, downstream of neuropeptide S (NPS; rs10734107), was significantly associated with sleep timing $(P=1.1 \mathrm{e}-5)$. In a separate analysis, the authors investigated the candidate SNPs from a previous study, ${ }^{18}$ and only one SNP in EPB41 (rs2985334) survived multiple testing correction ( $P=0.0062, \beta=5.3$ minutes). Although the $C A C N A 1 C$ association with sleep latency was not replicated in a Chronogen Consortium sample, ${ }^{37}$ another replication study found a $C A C N A 1 C$ variant (rs16929277, $P<0.05$ ) that was significantly associated with both sleep latency and sleep quality. ${ }^{21}$

Byrne et al also performed a GWAS specifically investigating caffeine-related insomnia alone and after controlling for a general insomnia score in the same Australian sample $(n=2,402) .{ }^{38}$ This study failed to find GWS SNPs, and many of the most significant associations were in intergenic regions for both analyses. The SNP most strongly associated with caffeine-related insomnia without controlling for general insomnia was an intronic SNP in Proline-rich membrane anchor 1 (PRIMA1) (rs6573232, $P=1.4 \mathrm{e}-6)$, a gene important for anchoring acetylcholinesterase to neuronal membranes. ${ }^{39}$ Although a number of the other most significant associations 
were SNPs in intergenic regions (eg, rs 7628219, $P=1.7 \mathrm{e}-6$; rs2065779, $P=2.5 \mathrm{e}-6$; and rs11706236, $P=3.6 \mathrm{e}-6)$, the authors also found associations with a set of intronic SNPs in microtubule-associated tumor suppressor Candidate 2 (MTUS2; including rs2388082, $P=1.4 \mathrm{e}-6$ ) and a SNP downstream of a melatonin receptor 1B (MTNR1B; rs10830964, $P=5.2 \mathrm{e}-6$ ). When general insomnia was controlled for, two of the most significant associations were in or near the guanylate binding protein 4 (GBP4) gene (rs521704, $P=1.9 \mathrm{e}-6$; rs561042, $P=6.2 \mathrm{e}-6)$, which hydrolyzes guanosine triphosphate, a nucleic acid that is structurally similar to adenosine. This study successfully replicated a previous association with an adenosine receptor SNP. ${ }^{32} \mathrm{~A}$ GO enrichment analysis also found a significant overrepresentation of genes associated with nucleic acid metabolism $(P=1 \mathrm{e}-4)$, suggesting that genes directly or indirectly affecting adenosine signaling and metabolism may be involved in caffeine-induced insomnia.

While these GWAS investigating insomnia/sleep quality failed to identify any variants that were GWS, the results highlighted pathways that may underlie the genetic etiology of insomnia, including genes involved in calcium signaling, neuronal function and adenosine metabolism. The use of a consistent and clinically validated definition of insomnia may aid the success of future GWAS for insomnia.

\section{GWAS for RLS}

RLS, one of the most common neurological disorders, is characterized by an irresistible urge to move one's body, usually the legs, and is accompanied by an uncomfortable and unpleasant sensation. ${ }^{40}$ Iron deficiency and disruption of the dopamine system are two of the most common medical conditions associated with RLS, ${ }^{41}$ with an age-independent prevalence of approximately $10 \% .{ }^{42}$ Twin studies have found that the symptoms of RLS are highly heritable, ranging from $44 \%$ to $63 \%$ (95\% confidence interval). ${ }^{43-45}$ Linkage analysis studies in families have revealed seven unique genetic loci for RLS: RLS1, chromosome 12q12-q21; RLS2, chromosome 14q13-21; RLS3, chromosome 9p24-p22; RLS4, chromosome 2q33; RLS5, chromosome 20p13; RLS6, chromosome19p13; and $R L S 7$, chromosome $16 \mathrm{p} 12.1 .^{46-52}$

To better characterize the genetic variation underlying RLS, Winkelmann et al conducted a GWAS for RLS. ${ }^{53}$ They found three loci significantly associated with RLS, including intronic variants in Myeloid ecotropic viral integration site 1 homeobox 1 (MEIS1; rs2300478, 8.1e-23) (chromosome 2 p14), a homeobox gene; variants in BTB domain containing 9 (BTBD9; rs9296249, 9.4e-13; rs9357271, 1.5e-12), a gene recently implicated in synaptic plasticity; ${ }^{54}$ and seven variants (the most significant being rs1026732, 1.4e-11) over a region including both Mitogen-activated protein kinase kinase 5 (MAP2K5), a protein kinase, and SKI family transcriptional corepressor 1 (SKOR1), a transcription factor. Together these variants accounted for over $50 \%$ of the risk for RLS. Another GWAS for RLS revealed two additional GWS variants (rs4626664, $P=5.9 \mathrm{e}-10$; rs 1975197, $P=5.8 \mathrm{e}-9$ ) that lie within the $5^{\prime}$-untranslated region of the protein tyrosine phosphatase receptor type D (PTPRD) gene, ${ }^{55}$ shown to be important for correct targeting of the motor neuron axon during mammalian axonogenesis. ${ }^{56}$ Interestingly, a different variant within PTPRD was significantly associated with periodic leg movements of sleep, a symptom of RLS, in an independent GWAS. ${ }^{57}$ A larger GWAS for RLS (approximately 5,000 cases) replicated these four peaks and found an additional two novel GWS loci, one (rs6747972, $P=9.0 \mathrm{e}-11$ ) in an intergenic region $1.3 \mathrm{Mb}$ downstream of MEISI and the other (rs3104767, $P=9.4 \mathrm{e}-19$ ) in an area of linkage disequilibrium containing TOX high mobility group box family member 3 (TOX3) and the non-coding RNA BC034767. ${ }^{58}$ This study found that these six loci together explain $6.8 \%$ of the known heritability of RLS, suggesting that additional loci were missed using this approach.

A number of replication studies have been conducted to confirm the associations of these loci with RLS, particularly focusing on those discovered initially (BTBD9, MEIS1, $M A P 2 K 5 / S K O R 1)$. Two case-control studies, one using a US sample and another using three European populations, successfully replicated the association of all three of these loci with RLS. ${ }^{59,60}$ When limited to a subset of sporadic cases, thus limiting power, the second study only replicated the BTBD9 association. ${ }^{60}$ Another case-control study in an American sample successfully replicated the association with both $B T B D 9$ and $M E I S 1$, but only found a trend toward significance for the variants in $M A P 2 K 5 / S K O R 1 .{ }^{61} \mathrm{~A}$ recent study investigating BTBD9, MEIS1, MAP2K5/SKOR1, and $P T P R D$ in a Korean case-control sample only successfully replicated the association with $B T B D 9 .{ }^{62}$ Another study only investigating the two nominated PTPRD SNPs in both RLS families and in a case-control sample, replicated the association between RLS and rs1975197 ( $P=0.02)$, but not rs4626664 $(P=0.6) .{ }^{63}$ A study using a small Czech sample did not replicate any of the previous associations with RLS, but this may be due to power issues. ${ }^{64}$ There is thus the strongest evidence for an association between $B T B D 9$ and RLS, followed by MEIS1 and MAP2K5/SKOR1.

It has recently been shown that SNPs found to have GWS associations with complex diseases are more likely 
Table I Summary of genome-wide significant associations

\begin{tabular}{|c|c|c|c|c|c|c|c|}
\hline $\begin{array}{l}\text { Genetic } \\
\text { variant }^{\mathrm{a}}\end{array}$ & Location & Gene & $P$-value & Pathology & Reference & Replication & Non-replication \\
\hline rs 1823068 & Intronic & $\begin{array}{l}\text { cAMP-specific } 3^{\prime}, 5^{\prime} \text {-cyclic } \\
\text { phosphodiesterase } 4 D\end{array}$ & $2.5 e-08$ & Sleep duration & 19 & NA & $20,22,23$ \\
\hline rsII046205 & Intronic & $\begin{array}{l}\text { ATP-binding cassette, } \\
\text { sub-family } C \text { member } 9\end{array}$ & $4.0 \mathrm{e}-08$ & Sleep duration & 20 & 21 & 22,23 \\
\hline rsl191685 & Intergenic & Paired box gene 8 & I.le-09 & Sleep duration & 23 & NA & NA \\
\hline rs4587207 & Intergenic & $\begin{array}{l}\text { Radiation-inducible immediate-early } \\
\text { gene IEX-I, flotillin-I, long } \\
\text { non-coding RNA (LINC00243) }\end{array}$ & $2.0 \mathrm{e}-08$ & Sleep duration & 23 & NA & NA \\
\hline rs2300478 & Intronic & $\begin{array}{l}\text { Myeloid ecotropic viral } \\
\text { integration site I homeobox I }\end{array}$ & $8.1 \mathrm{e}-23$ & RLS & 53 & $55,58-61$ & 62,64 \\
\hline rs9296249 & Intronic & BTB domain containing 9 & $9.4 \mathrm{e}-13$ & RLS & 53 & $55,58-62$ & 64 \\
\hline rs1026732 & Intronic & $\begin{array}{l}\text { Mitogen-activated protein } \\
\text { kinase kinase } 5 \text {, SKI family } \\
\text { transcriptional corepressor I }\end{array}$ & $1.4 \mathrm{e}-1 \mathrm{I}$ & RLS & 53 & $55,58-60$ & $61,62,64$ \\
\hline rs4626664 & $5^{\prime}$-UTR & $\begin{array}{l}\text { Protein tyrosine phosphatase } \\
\text { receptor type } D\end{array}$ & $5.9 e-10$ & RLS & 55 & $57,58,63$ & NA \\
\hline rs6747972 & Intergenic & $\begin{array}{l}\text { Myeloid ecotropic viral } \\
\text { integration site I homeobox I }\end{array}$ & $9.0 \mathrm{e}-11$ & RLS & 58 & NA & NA \\
\hline rs3104767 & Intergenic & $\begin{array}{l}\text { TOX high mobility group box } \\
\text { family member } 3 \text {, non-coding } \\
\text { RNA (BC034767) }\end{array}$ & $9.0 \mathrm{e}-11$ & RLS & 58 & NA & NA \\
\hline $\begin{array}{l}\text { DQBI*06:02 } \\
\left(\mathrm{HLA00646)^{ \textrm {b } }}\right.\end{array}$ & Coding & $\begin{array}{l}\text { Major histocompatibility } \\
\text { complex, class II, DQ beta I }\end{array}$ & $4.7 e-47$ & Narcolepsy & 98 & $87,107,108$ & NA \\
\hline rs5770917 & Intergenic & $\begin{array}{l}\text { Carnitine palmitoyltransferase IB, } \\
\text { choline kinase } \beta\end{array}$ & $4.4 \mathrm{e}-07^{\mathrm{c}}$ & Narcolepsy & 98 & 102 & 106 \\
\hline rs 16826005 & Intronic & NCK-associated protein 5 & $1.0 \mathrm{e}-07^{\mathrm{c}}$ & Narcolepsy & 102 & NA & 108 \\
\hline rsII54I55 & Intronic & T-cell receptor alpha & $2.8 e-22$ & Narcolepsy & 103 & $87,106-108$ & 105 \\
\hline rs2305795 & $3^{\prime}-$ UTR & Purinergic receptor subtype $2 Y_{11}$ & $6.1 \mathrm{e}-10$ & Narcolepsy & 105 & 106,108 & 87 \\
\hline rs34593439 & Intronic & Cathepsin $\mathrm{H}$ & $1.8 \mathrm{e}-08$ & Narcolepsy & 107 & NA & NA \\
\hline rs75537II & Intergenic & $\begin{array}{l}\text { Tumor necrosis factor } \\
\text { superfamily member } 4\end{array}$ & 4.1 e-08 & Narcolepsy & 107 & NA & 87 \\
\hline rs9648789 & Intergenic & T-cell receptor $\beta$ locus & $3.7 e-09$ & Narcolepsy & 108 & NA & NA \\
\hline rs 10995245 & Intronic & Zinc finger gene 365 & $\mid .2 \mathrm{e}-1 \mathrm{I}$ & Narcolepsy & 108 & NA & NA \\
\hline rs225293I & Intergenic & $\begin{array}{l}\text { Interleukin-10 receptor } \beta \text {, } \\
\text { interferon }(\alpha, \beta, \omega) \text { receptor I }\end{array}$ & $2.2 \mathrm{e}-09$ & Narcolepsy & 108 & NA & NA \\
\hline
\end{tabular}

Notes: aAll genetic variants are designated by the dbSNP ID, minus DQ0I*06:02, which is designated by the HLA ID. If more than one SNP was identified that reached RWS for a study, only the most significant SNP in the study is represented; bQ0 ${ }^{\mathrm{B}} 06: 02$ is thought to mediate the majority of the effects of the HLA locus, alone or as a haplotype, but other variants also play a role (see references 6, 84-86); 'the SNPs rs57709I7 and rs I6826005 are included in the graph as they reached GWS within the individual studies $(P<6.4 \mathrm{e}-5$ and $P<5 \mathrm{e}-7$, respectively), but it is important to note that they do not survive the $P<5 \mathrm{e}-8$ now more commonly accepted as a statistical cut-off for GWS.

Abbreviations: RLS, restless leg syndrome; SNP, single nucleotide; NA, not available; UTR, untranslated region; GWS, genome-wide significance.

to affect gene expression, and in turn represent expression quantitative trait loci (eQTLs). ${ }^{65,66}$ To this end, the presence of eQTLs has been used successfully to prioritize subthreshold GWAS loci for a range of complex diseases, such as Crohn's disease. ${ }^{67}$ Using a similar approach in two independent RLS cohorts, researchers used mRNA from peripheral blood to prioritize the 332 most significantly associated SNPs from the largest RLS GWAS. ${ }^{68}$ Of the 23 cis-eQTLs that overlapped between the two cohorts, eleven were located in known RLS-associated loci. None of the 12 novel eQTL SNPs were significantly associated with RLS, but the transcription factor, de-etiolated homolog 1 (DET1), a gene involved in ubiquitination and subsequent degradation of target proteins, was nominally associated with RLS ( $P=0.04)$.

It is often difficult to determine if a GWS SNP is in fact the causal variant underlying the association or instead is in linkage disequilibrium with the true causal variant/s. Recently, it has been proposed that rare, functional variants may underlie these associations as well as explaining some of the missing heritability in GWAS. ${ }^{69-71}$ Sequencing of the coding regions of $B T B D 9$ and $M E I S 1$ revealed a rare novel non-synonymous variant in MEIS1, p.R272H (ss107795884), which segregated, although not significantly, in a small RLS pedigree. ${ }^{72}$ Resequencing of the coding regions and exon-intron boundaries 
from the previously described GWAS for $\mathrm{RLS}^{58}$ revealed 49 novel, rare alleles (minor allele frequency $<5 \%$ ), which together were overrepresented in the RLS cases compared with a control sample. ${ }^{73}$ Non-synonymous SNPS within MEIS1 were significantly enriched in the RLS cases, with nominally significant enrichment for the other six investigated genes. The 13 non-synonymous variants found within the canonical MEIS1 isoform (ENST00000272369) were functionally characterized using an assay for neuronal development in zebrafish; four were found to be hypomorphic and six to be null variants. There was a significant excess of these loss-of-function alleles in RLS patients. Though further research is required to determine the functional variants and their associated mechanisms of action, together these studies have implicated genes associated with neuronal development and synaptic plasticity, among other pathways, as the potential basis of the genetic etiology of RLS.

\section{GWAS for OSA}

OSA is a common disorder characterized by repetitive episodes of upper airway obstruction or airway collapse that occurs during sleep, which leads to oxygen desaturation, disrupted/fragmented sleep, and daytime sleepiness. ${ }^{74}$ Many factors may contribute to this airway obstruction, including obesity, large necks and nasal obstruction caused by a deviated septum. Genetic factors are known to contribute to OSA, with heritability estimates for the apnea hypopnea index (AHI), a measure of OSA, of $32 \%$ in one study. ${ }^{75}$ Several genetic variants have been identified in candidate gene studies of OSA, yet few have been successfully replicated. Three genes with the strongest evidence of involvement in OPA include apolipoprotein $\mathrm{E}(A P O E)$, angiotensin-converting enzyme $(A C E)$, and tumor necrosis factor alpha $(T N F \alpha)$, but recent meta-analyses have only validated the association with $T N F \alpha{ }^{76,77}$

Given the close association of OPA with obesity, commonly measured using body mass index, it is necessary to control for obesity in any association models for OPA to determine if the association is truly unique to OPA. Genomewide univariate family linkage studies for OSA have revealed only weak candidate loci for AHI, independent of body mass index, ${ }^{75,78}$ while bivariate analysis revealed a linkage peak for respiratory disturbance index and AHI at 19p13.4 (logarithm of odds , 3.04), which includes a killer cell immunoglobulinlike receptor gene cluster. ${ }^{79}$

A large candidate gene association study for OSA using the Cleveland Family Study, consisting of EuropeanAmerican and African-Americans subsamples, investigated over 45,000 SNPs from approximately 2,100 candidate genes. ${ }^{80}$ Within the African American subset, two SNPs survived multiple testing corrections: rs11126184 ( $P=1.4 \mathrm{e}-6)$, a SNP in the pleckstrin ( $P L E K)$ gene was associated with OSA, and rs7030789 ( $P=4.6 \mathrm{e}-6)$, a SNP in the lysophosphatidic acid receptor 1 (LPARI) gene was associated with AHI. PLEK has a role in protein kinase $\mathrm{C}$ signaling and LPAR1 is a $\mathrm{G}$ protein-coupled receptor. Within the European subsample, rs1409986 ( $P=2.2 \mathrm{e}-4)$, a SNP in the prostaglandin E2 receptor (PTGER3) gene, was significantly associated with OSA. All three of these SNPs remained significant in analysis models including body mass index. LPAR1 and PTGER3 associations, but not PLEK, were replicated in an independent sample. A significant enrichment in phosphorylation of the STAT protein family and insulin signaling GO functional categories was found, suggesting that these pathways might warrant further investigation for genetic etiology of OPA. ${ }^{81}$

As GWAS often miss rare, causal variants that might underlie the heritability for a complex disorder, ${ }^{69}$ researchers are increasingly turning to other methods, such as exome sequencing $^{82}$ and selected resequencing of GWAS loci ${ }^{71}$ to detect these variants. A recent study used exome sequencing in four probands that presented with intellectual disability, developmental delay, and mildly dysmorphic facial features, of which three probands also had OSA. ${ }^{82}$ This study revealed four truncating mutations in the AT-hook, DNA-binding motif containing 1 ( $A H D C 1$ ) gene, an uncharacterized human transcription factor, to be associated with these traits.

As a range of factors influence OSA, genes underlying OSA can affect one or more of these factors, making it critical to carefully consider which factors to include in any GWAS approach for OSA. This consideration may help to reveal additional loci for the disorder that may be specific or shared across these associated factors.

\section{GWAS for narcolepsy}

Narcolepsy is a sleep disorder that affects approximately 1 in 2,000 individuals. ${ }^{6}$ It is characterized by irresistible excessive daytime sleepiness as well as cataplexy, the sudden loss of muscle tone in response to strong emotions. ${ }^{40}$ Family studies have shown up to a 40 times higher relative risk of narcolepsy in first-degree family members of patients and twin studies estimate approximately 35\% heritability; together this suggests that the etiology of narcolepsy has a genetic component. ${ }^{6,83}$

Of all the sleep disorders, narcolepsy is the one for which there has been particular progress in terms of specifying 
candidate genes. It has been reported that a very high proportion $(>85 \%)$ of those suffering narcolepsy with cataplexy carry a specific human leukocyte antigen (HLA) allele (HLA-DQB1) compared with just $12 \%-38 \%$ in the general population. ${ }^{6}$ Additional studies show that a number of HLA class II region alleles play a complex role in the genetic predisposition to narcolepsy. ${ }^{84-86} \mathrm{~A}$ recent study found that the $D Q B 1^{* 06: 02}$ allele confers an extremely high risk for narcolepsy with cataplexy (odds ratio 251) ${ }^{87}$ Homozygotes for this allele had higher levels of HLA-DQ mRNA and protein expression in white blood cells, suggesting a potential functional consequence of this allele. ${ }^{88}$ Due to its association with HLA alleles, it is thought that narcolepsy could be an autoimmune disease. This hypothesis has been strengthened by the findings of auto-antibodies close to the time of disease onset $^{89,90}$ and the increase in the number of narcolepsy cases following the $2009 \mathrm{H} 1 \mathrm{~N} 1$ vaccination. ${ }^{91}$

Two independent animal models have implicated the hypocretin (orexin) system in narcolepsy: a knock-out mouse missing the hypocretin gene displayed narcolepsy-like symptoms $^{92}$ and disruption of a hypocretin receptor caused narcolepsy in a canine model..$^{93}$ It is now believed that the majority of human cases of narcolepsy are due to the loss of hypocretin-producing neurons in the hypothalamus; ${ }^{94-96}$ the loss of these neurons is likely caused by a combination of environmental factors and a genetic susceptibility based, at least in part, on the HLA locus, ${ }^{97}$ which might cause these cells to be the target of autoimmune attack.

GWAS in narcolepsy have generally served to strengthen the associations with HLA as well as nominate potential novel pathways. One of the first GWAS for narcolepsy replicated the association with the HLA locus and also found GWS association with a SNP between the carnitine palmitoyltransferase $1 \mathrm{~B}(C P T 1 B)$ and choline kinase $\beta$ genes $(\mathrm{CHK} \beta$; rs5770917, $P=4.4 \mathrm{e}-7)$ that decreases the expression of these two genes. ${ }^{98} \mathrm{CPT} 1 \mathrm{~B}$ is an enzyme involved in $\beta$-oxidation of long-chain fatty acids, a pathway involved in regulating theta frequency during rapid eye movement sleep. CHK $\beta$ is an enzyme involved in the metabolism of the acetylcholine precursor choline. Both rs5770917 $(P=3.6 \mathrm{e}-3)$ and variants in the HLA locus ( $P=9.2 \mathrm{e}-11)$ were also significantly associated with essential hypersomnia, a group of disorders related to narcolepsy. ${ }^{99}$ Consistent with these findings, rs5770917 was associated with decreased serum levels of $C P T 1 B$ mRNA expression ${ }^{100}$ and oral administration of L-carnitine decreased daytime sleep times in narcoleptic patients in a double-blind study. ${ }^{101}$ In addition to $C P T 1 B$, a GWAS for HLA-DQB1*06:02 in negative essential hypersomnia found another novel significant association with NCK-associated protein 5, a protein coding gene with no known function (rs16826005, $P=1 \mathrm{e}-7){ }^{102}$

GWAS have also strengthened the autoimmune hypothesis for narcolepsy, with a number of significant associations found in genes important for regulating immune function. One GWAS for narcolepsy with individuals that were $D Q B 1 * 0602$-positive found significant associations with variants in the T-cell receptor alpha $(T R C \alpha)$ locus (rs1154155, $P<1 \mathrm{e}-21$ ), a receptor responsible for responding to HLA-peptide presentation. ${ }^{103}$ This variant was also significantly associated with essential hypersomnia specifically in individuals with the $D R B 1 * 1501-D Q B 1 * 0602$ haplotype $(P=0.04) .{ }^{104}$ Another GWAS for narcolepsy found a GWS association with a SNP in the 3 -untranslated region of purinergic receptor subtype $2 \mathrm{Y}_{11}(P 2 R Y 11)$ gene (rs2305795, $P=6.1 \mathrm{e}-10),{ }^{105}$ an important regulator of immune cell survival, that regulates its own expression in T-lymphocytes and natural killer cells. The associations of the $T R C \alpha(\mathrm{rs} 1154155)$ and P2RY11 (rs2305795) variants with narcolepsy were replicated in a Chinese sample, while the association with the $C P T 1 B / C H K \beta$ variant (rs5770917) was not. ${ }^{106}$ A custom genotyping array for the fine mapping of DNA loci involved in immune function (ImmunoChip) was used to genotype a sample consisting of hypocretin-deficient narcoleptic patients $(n=1,886)$ and replicated the GWS associations with the HLA loci and the TRC $\alpha$ locus (rs1154155, $P<1 \mathrm{e}-30$ ). It also identified two novel loci: cathepsin H (CTSH; rs34593439, $P=1.8 \mathrm{e}-8$ ), a gene involved the in degradation of lysosomal proteins, and tumor necrosis factor (ligand) superfamily member 4 (TNFSF4), a cytokine involved in interactions with T-cells (rs7553711, $P=4.1 \mathrm{e}-8) .{ }^{107} \mathrm{~A}$ GWAS in a Chinese narcolepsy sample also replicated the association with the HLA locus and the TRC $\alpha$ locus (rs1154155, $P<1 \mathrm{e}-30)$ and found an association with a wider set of SNPs at the $P 2 R Y 11 A$ locus (including rs $1551570, P=3.8 \mathrm{e}-10$ ). This study additionally found three novel loci: the T-cell receptor $\beta$ locus, TCR $\beta$ (rs9648789, $P=3.7 \mathrm{e}-9$ ); the transcription factor zinc finger gene 365, ZNF365 (rs10995245, $P=1.2 \mathrm{e}-11$ ); and a SNP between two genes associated with immune function, IL10R $\beta$-IFNAR1 (rs2252931, P=2.2e-9). ${ }^{108}$ A recent large GWAS for narcolepsy replicated an association with the HLA locus (rs2858884, $P=2 \mathrm{e}-9$ ) and the $T R C \alpha$ locus (rs1154155, $P=2 \mathrm{e}-8) .{ }^{87}$ Finally, a recent study investigating copy number variants in narcolepsy patients found an association of copy number variants within Parkinson protein 2 with narcolepsy, as well as enrichment of copy number variants in genes involved in immune function. ${ }^{109}$ Together, these studies 
highlight the involvement of immune function in the etiology of narcolepsy.

One additional GWAS investigated associations with individual narcolepsy symptoms. ${ }^{110}$ Although it failed to find any GWS associations, it did find strong associations of a SNP in $U B X N 2 B$ (rs2859998, $P=1.3 \mathrm{e}-7$ ), a gene involved in Golgi biogenesis, with age of onset of excessive daytime sleepiness and a SNP in TEAD4 (rs12425451, $P=2.0 \mathrm{e}-7)$, a transcription factor, with age of cataplexy onset.

\section{Future directions}

GWAS have had some success in identification of the genetic variation underlying sleep characteristics and sleep disorders; however, additional research is required to validate, refine, and further this approach. GWAS results provide powerful evidence to support the role of a genetic variant in a disorder, but do have limitations. In particular: they often fail to account for all of the heritability associated with a disorder; they rarely find the causal variant, thus requiring functional studies to validate any findings; and due to stringent multiple testing corrections, the statistical cut-offs for GWAS are so high that they can lead to high rates of false negatives. ${ }^{10}$ In order to fully identify and characterize the genetic factors underlying sleep and sleep disorders, complementary methods are needed to address these shortcomings, as outlined below.

\section{Missing heritability}

For the majority of complex disorders, the genes specified by GWAS account for a proportion of the underlying genetic heritability. This "missing heritability" may be in part due to such factors as an insufficient power to detect variation with a low effect size on the disorder, epistasis, failure to detect structural variation, such as the role of copy number variations in influencing a trait, and rare genetic variants. ${ }^{111}$ With the cost of next-generation sequencing rapidly decreasing, a number of techniques, including targeted and exome sequencing, should help to reveal variation that may be missed using a GWAS approach.

\section{Determining the functional variants}

GWAS rarely reveal the causal genetic variation which is crucial to understanding the biological mechanism underlying these associations. To characterize the functional role that GWAS genes play in the disease mechanism we must turn to other methods, such as targeted resequencing of a GWAS locus followed by validation using cellular and animal models. Resequencing of GWAS loci have revealed rare variants that can be associated with a particular disorder, individually or collectively. ${ }^{70,71}$ Furthermore, animal models have successfully validated various GWAS findings. ${ }^{20}$ With the development of genome-wide or next-generation sequencing approaches to determine the genetic variants underlying various sleep-related phenotypes, animal models will likely play a greater role in validating these findings.

\section{Mining GWAS data}

Ever increasing sample sizes in GWAS have revealed many additional low effect size variants that previously evaded detection, although more could be done to validate the strong but non-GWS significant associations with disease. A number of approaches have been used to further mine subthreshold GWAS loci. GWS SNPs are more likely to affect gene expression ${ }^{67}$ and lie within DNase I-hypersensitive sites. ${ }^{112}$ The presence of cis eQTLs has been used successfully to prioritize subthreshold GWAS loci for a range of complex diseases. ${ }^{67,68}$ The use of data from public databases, such as the information on regulatory elements available in the Encyclopedia of DNA Elements, has led to the identification of novel GWAS loci. ${ }^{113}$ Furthermore, as GWAS primarily focus on single-gene analysis, they can miss effects of a group of significant variants on a shared pathway. To address this, researchers commonly try to detect enrichment of GO terms within a gene set, commonly investigating all nominally significant associations, to identify shared biological processes or molecular functions underlying a trait or pathology. ${ }^{114,115}$ In the absence of replicated variants across GWAS, using a gene set enrichment analysis can additionally be used across studies to determine the consistently detected pathways. ${ }^{116}$

\section{Summary}

Given the importance of sleep to our well-being, understanding the genetic and environmental factors that underlie sleep and sleep disorders is essential to developing better prevention and treatment for these disorders. GWAS have successfully identified a number of genetic variants associated with sleep characteristics and sleep disorders, but further work need to be done to fully identify and characterize the genetic factors underlying sleep and sleep disorders. Existing GWAS loci may be validated and additional loci discovered through the refinement of phenotypes investigated, strengthening the power available, and by further mining of the subthreshold GWS significant loci using additional datasets. The use of next-generation sequencing to determine the functional 
genetic variants underlying various sleep-related phenotypes, combined with the use of animal models, will be critical in determining the biological mechanism underlying these associations.

\section{Acknowledgments}

The author thanks Drs Alison Landman and Alice Gregory for critically reading the manuscript. MJP was supported by the Medical Research Council.

\section{Disclosure}

The author reports no conflicts of interest in this work.

\section{References}

1. Bastien CH, Morin CM. Familial incidence of insomnia. J Sleep Res. 2000;9:49-54.

2. Beaulieu-Bonneau S, LeBlanc M, Merette C, Dauvilliers Y, Morin CM. Family history of insomnia in a population-based sample. Sleep. 2007;30:1739-1745.

3. Dauvilliers Y, Morin C, Cervena K, et al. Family studies in insomnia. J Psychosom Res. 2005;58:271-278.

4. Winkelmann J, Wetter TC, Collado-Seidel V, et al. Clinical characteristics and frequency of the hereditary restless legs syndrome in a population of 300 patients. Sleep. 2000;23:597-602.

5. Mathur R, Douglas NJ. Family studies in patients with the sleep-apnea hypopnea syndrome. Ann Intern Med. 1995;122:174-178.

6. Mignot E. Genetic and familial aspects of narcolepsy. Neurology. 1998;50:S16-S22.

7. Barclay NL, Gregory AM. Quantitative genetic research on sleep: a review of normal sleep, sleep disturbances and associated emotional, behavioural, and health-related difficulties. Sleep Med Rev. 2013;17:29-40

8. Sehgal A, Mignot E. Genetics of sleep and sleep disorders. Cell. 2011;46:194-207.

9. Cirelli C. The genetic and molecular regulation of sleep: from fruit flies to humans. Nat Rev Neurosci. 2009;10:549-560.

10. Pearson TA, Manolio TA. How to interpret a genome-wide association study. JAMA. 2008;299:1335-1344.

11. Watson NF, Buchwald D, Vitiello MV, Noonan C, Goldberg J. A twin study of sleep duration and body mass index. $J$ Clin Sleep Med. 2010;6:11-17.

12. Watson NF, Harden KP, Buchwald D, et al. Sleep duration and body mass index in twins. Sleep. 2012;35:597-603.

13. Benedetti F, Serretti A, Colombo C, et al. Influence of CLOCK gene polymorphism on circadian mood fluctuation and illness recurrence in bipolar depression. Am J Med Genet B Neuropsychiatr Genet. 2003;123B:23-26.

14. Allebrandt KV, Teder-Laving M, Akyol M, et al. CLOCK gene variants associate with sleep duration in two independent populations. Biol Psychiatry. 2010;67:1040-1047.

15. Parsons MJ, Lester KJ, Barclay NL, et al. Polymorphisms in the circadian expressed genes PER3 and ARNTL2 are associated with diurnal preference and GN $\beta 3$ with sleep measures. J Sleep Res. 2014;23:595-604.

16. He Y, Jones CR, Fujiki N, et al. The transcriptional repressor DEC2 regulates sleep length in mammals. Science. 2009;325:866-870.

17. Pellegrino R, Kavakli IH, Goel N, et al. A novel BHLHE41 variant is associated with short sleep and resistance to sleep deprivation in humans. Sleep. 2014;37:1327-1336.

18. Gottlieb DJ, O'Connor GT, Wilk JB. Genome-wide association of sleep and circadian phenotypes. BMC Med Genet. 2007;8:S9.
19. Li JD, Hu WP, Boehmer L, et al. Attenuated circadian rhythms in mice lacking the prokineticin 2 gene. J Neurosci. 2006;26:11615-11623.

20. Allebrandt KV, Amin N, Muller-Myhsok B, et al. AK(ATP) channel gene effect on sleep duration: from genome-wide association studies to function in Drosophila. Mol Psychiatry. 2013;18:122-132.

21. Parsons MJ, Lester KJ, Barclay NL, Nolan PM, Eley TC, Gregory AM. Replication of genome-wide association studies (GWAS) loci for sleep in the British G1219 cohort. Am J Med Genet B Neuropsychiatr Genet. 2013;162B:431-438.

22. Ollila HM, Kettunen J, Pietiläinen O, et al. Genome-wide association study of sleep duration in the Finnish population. J Sleep Res. 2014;23: 609-618.

23. Gottlieb DJ, Hek K, Chen TH, et al. Novel loci associated with usual sleep duration: the CHARGE consortium genome-wide association study. Mol Psychiatry. December 2, 2014. [Epub ahead of print.]

24. Gregory AM, Cousins JC, Forbes EE, et al. Sleep items in the child behavior checklist: a comparison with sleep diaries, actigraphy, and polysomnography. J Am Acad Child Adolesc Psychiatry. 2011;50: 499-507.

25. De Gennaro L, Marzano C, Fratello F, et al. The electroencephalographic fingerprint of sleep is genetically determined: a twin study. Ann Neurol. 2008;64:455-460.

26. American Psychiatric Association. Diagnostic and Statistical Manual of Mental Disorders: DSM-5. Washington, DC, USA: American Psychiatric Association; 2013

27. Ohayon M. Epidemiological study on insomnia in the general population. Sleep. 1996;19:S7-S15.

28. Watson NF, Goldberg J, Arguelles L, Buchwald D. Genetic and environmental influences on insomnia, daytime sleepiness, and obesity in twins. Sleep. 2006;29:645-649.

29. Gehrman PR, Pfeiffenberger C, Byrne E. The role of genes in the insomnia phenotype. Sleep Med Clin. 2013;8:323-331.

30. Serretti A, Benedetti F, Mandelli L, et al. Genetic dissection of psychopathological symptoms: insomnia in mood disorders and CLOCK gene polymorphism. Am J Med Genet B Neuropsychiatr Genet. 2003;121B:35-38.

31. Buhr A, Bianchi MT, Baur R, et al. Functional characterization of the new human GABA(A) receptor mutation beta 3(R192H). Hum Genet. 2002;111:154-160.

32. Rétey JV, Adam M, Khatami R, et al. A genetic variation in the adenosine A2A receptor gene contributes to individual sensitivity to caffeine effects on sleep. Clin Pharmacol Ther. 2007;81: 692-698.

33. Deuschle M, Schredl M, Schilling C, et al. Association between a serotonin transporter length polymorphism and primary insomnia. Sleep. 2010;33:343-347.

34. Barclay NL, Eley TC, Mill J, et al. Sleep quality and diurnal preference in a sample of young adults: associations with 5HTTLPR, PER3, and CLOCK 3111. Am J Med Genet B Neuropsychiatr Genet. 2011;156:681-690.

35. Ban HJ, Kim SC, Seo J, Kang HB, Choi JK. Genetic and metabolic characterization of insomnia. PLoS One. 2011;6:e18455.

36. Paganoni S, Bernstein J, Ferreira A. Ror1-Ror2 complexes modulate synapse formation in hippocampal neurons. Neuroscience. 2010;165:1261-1274.

37. Byrne EM, Gehrman PR, Medland SE, et al. A genome-wide association study of sleep habits and insomnia. Am J Med Genet B Neuropsychiatr Genet. 2013;162B:439-451.

38. Byrne EM, Johnson J, McRae AF, et al. A genome-wide association study of caffeine-related sleep disturbance: confirmation of a role for a common variant in the adenosine receptor. Sleep. 2012;35: 967-975.

39. Perrier AL, Massoulié J, Krejci E. PRiMA: the membrane anchor of acetylcholinesterase in the brain. Neuron. 2002;33:275-285.

40. American Academy of Sleep Medicine. International Classification of Sleep Disorders. 3rd ed. Darien, IL, USA: American Academy of Sleep Medicine; 2014. 
41. Winkelman JW, Allen RP, Tenzer P, Hening W. Restless legs syndrome: nonpharmacologic and pharmacologic treatments. Geriatrics. 2007;62: $13-16$.

42. Allen RP, Picchietti D, Hening WA, Trenkwalder C, Walters AS, Montplaisi J; Restless Legs Syndrome Diagnosis and Epidemiology workshop at the National Institutes of Health; International Restless Legs Syndrome Study Group. Restless legs syndrome: diagnostic criteria, special considerations, and epidemiology. Sleep Med. 2003;4: 101-119.

43. Desai AV, Cherkas LF, Spector TD, Williams AJ. Genetic influences in self-reported symptoms of obstructive sleep apnoea and restless legs. Twin Res. 2004;7:589-595.

44. Ondo WG, Vuong KD, Wang Q. Restless legs syndrome in monozygotic twins. Neurology. 2000;55:1404-1406.

45. Xiong L, Jang K, Montplaisir J, et al. Canadian restless legs syndrome twin study. Neurology. 2007;68:1631-1633.

46. Chen S, Ondo WG, Rao S, et al. Genome-wide linkage scan identifies a novel susceptibility locus for restless legs syndrome on chromosome 9p. Am J Hum Genet. 2004;74:876-885.

47. Desautels A, Turecki G, Montplaisir J, Sequeira A, Verner A, Rouleau GA. Identification of a major susceptibility locus for restless legs syndrome on chromosome 12q. Am J Hum Genet. 2001;69: 1266-1270.

48. Bonati MT, Ferini-Strambi L, Aridon P, Oldani A, Zucconi M, Casari G. Autosomal dominant restless legs syndrome maps on chromosome 14q. Brain. 2003;126:1485-1492.

49. Pichler I, Marroni F, Volpato CB, et al. Linkage analysis identifies a novel locus for restless legs syndrome on chromosome $2 \mathrm{q}$ in a South Tyrolean population isolate. Am J Hum Genet. 2006;79:716-723.

50. Levchenko A, Provost S, Montplaisir JY, et al. A novel autosomal dominant restless legs syndrome locus maps to chromosome $20 \mathrm{p} 13$. Neurology. 2006;67:900-901.

51. Kemlink D, Plazzi G, Vetrugno R, et al. Suggestive evidence for linkage for restless legs syndrome on chromosome 19p13. Neurogenetics. 2008;9:75-82.

52. Levchenko A, Montplaisir JY, Asselin G, et al. Autosomal-dominant locus for restless legs syndrome in French-Canadians on chromosome 16p12.1. Mov Disord. 2009;24:40-50.

53. Winkelmann J, Schormair B, Lichtner P, et al. Genome-wide association study of restless legs syndrome identifies common variants in three genomic regions. Nat Genet. 2007;39:1000-1006.

54. DeAndrade MP, Zhang L, Doroodchi A, et al. Enhanced hippocampal long-term potentiation and fear memory in Btbd9 mutant mice. PLoS One. 2012;7:e35518.

55. Schormair B, Kemlink D, Roeske D, et al. PTPRD is associated with restless legs syndrome. Nat Genet. 2008;40:946-948.

56. Uetani N, Chagnon MJ, Kennedy TE, Iwakura Y, Tremblay ML. Mammalian motoneuron axon targeting requires receptor protein tyrosine phosphatases sigma and delta. J Neurosci. 2006;26: $5872-5880$

57. Stefansson H, Rye DB, Hicks A, et al. A genetic risk factor for periodic limb movements in sleep. N Engl J Med. 2007;357:639-647.

58. Winkelmann J, Czamara D, Schormair B, et al. Genome-wide association study identifies novel restless legs syndrome susceptibility loci on 2p14 and 16q12.1. PLoS Genet. 2011;7:e1002171.

59. Yang Q, Li L, Chen Q, Foldvary-Schaefer N, Ondo WG, Wang QK. Association studies of variants in MEIS1, BTBD9, and MAP2K5/ SKOR1 with restless legs syndrome in a US population. Sleep Med. 2011;12:800-804.

60. Kemlink D, Polo O, Frauscher B, et al. Replication of restless legs syndrome loci in three European populations. J Med Genet. 2009;46: 315-318.

61. Vilarino-Güell C, Farrer MJ, Lin SC. A genetic risk factor for periodic limb movements in sleep. N Engl J Med. 2008;358:425-427.

62. Kim MK, Cho YW, Shin WC, et al. Association of restless legs syndrome variants in Korean patients with restless legs syndrome. Sleep. 2013;36:1787-1791.
63. Yang Q, Li L, Yang R, et al. Family-based and population-based association studies validate PTPRD as a risk factor for restless legs syndrome. Mov Disord. 2011;26:516-519.

64. Vávrová J, Kemlink D, Sonka K, et al. Restless legs syndrome in Czech patients with multiple sclerosis: an epidemiological and genetic study. Sleep Med. 2012;13:848-851.

65. Nicolae DL, Gamazon E, Zhang W, Dolan ME, Cox NJ. Trait-associated SNPs are more likely to be eQTLs: annotation to enhance discovery from GWAS. PLoS Genet. 2010;6:e1000888.

66. Richards AL, Jones L, Moskvina V, et al. Schizophrenia susceptibility alleles are enriched for alleles that affect gene expression in adult human brain. Mol Psychiatry. 2012;17:193-201.

67. Fransen K, Visschedijk MC, van Sommeren S, et al. Analysis of SNPs with an effect on gene expression identifies UBE2L3 and BCL3 as potential new risk genes for Crohn's disease. Hum Mol Genet. 2010;19:3482-3488.

68. Schulte EC, Schramm K, Schurmann C, et al. Blood cis-eQTL analysis fails to identify novel association signals among sub-threshold candidates from genome-wide association studies in restless legs syndrome. PLoS One. 2014;9:e98092.

69. Maher B. Personal genomes: the case of the missing heritability. Nature. 2008;456:18-21.

70. Bonnefond A, Clément N, Fawcett K, et al. Rare MTNR1B variants impairing melatonin receptor $1 \mathrm{~B}$ function contribute to type 2 diabetes. Nat Genet. 2012;44:297-301.

71. Rivas MA, Beaudoin M, Gardet A, et al. Deep resequencing of GWAS loci identifies independent rare variants associated with inflammatory bowel disease. Nat Genet. 2011;43:1066-1073.

72. Vilariño-Güell C, Chai H, Keeling BH, et al. MEIS1 p.R272H in familial restless legs syndrome. Neurology. 2009;273:243-245.

73. Schulte EC, Kousi M, Tan PL, et al. Targeted resequencing and systematic in vivo functional testing identifies rare variants in MEIS1 as significant contributors to restless legs syndrome. Am J Hum Genet. 2014;95:85-95.

74. White DP. Pathogenesis of obstructive and central sleep apnea. Am J Respir Crit Care Med. 2005;172:1363-1370.

75. Palmer LJ, Buxbaum SG, Larkin EK, et al. Whole genome scan for obstructive sleep apnea and obesity in African-American families. Am J Respir Crit Care Med. 2004;169:1314-1321.

76. Lee P, Douglas NJ, Riha RL. The association of angiotensin-converting enzyme gene insertion/deletion polymorphisms with OSA: a metaanalysis. Eur Respir J. 2012;40:394-399.

77. Varvarigou V, Dahabreh IJ, Malhotra A, Kales SN. A review of genetic association studies of obstructive sleep apnea: field synopsis and metaanalysis. Sleep. 2011;34:1461-1468.

78. Palmer LJ, Buxbaum SG, Larkin E, et al. A whole-genome scan for obstructive sleep apnea and obesity. Am J Hum Genet. 2003;72: 340-350.

79. Relf BL, Larkin EK, De Torres C, Baur LA, Christodoulou J, Waters KA. Genome-wide linkage of obstructive sleep apnoea and high-density lipoprotein cholesterol in a Filipino family. J Sleep Res. 2010;19: 349-357.

80. Patel SR, Goodloe R, De G, et al. Association of genetic loci with sleep apnea in European Americans and African-Americans. PLoS One. 2012;7:e48836.

81. Liu Y, Patel S, Nibbe R, et al. Systems biology analyses of gene expression and genome wide association study data in obstructive sleep apnea. Pac Symp Biocomput. 2011;14-25.

82. Xia F, Bainbridge MN, Tan TY, et al. De novo truncating mutations in AHDC1 in individuals with syndromic expressive language delay, hypotonia, and sleep apnea. Am J Hum Genet. 2014;94:784-789.

83. Kaprio J, Hublin C, Partinen M, Heikkilä K, Koskenvuo M. Narcolepsy-like symptoms among adult twins. J Sleep Res. 1996;5: $55-60$.

84. Hor H, Kutalik Z, Dauvilliers Y, et al. Genome-wide association study identifies new HLA class II haplotypes strongly protective against narcolepsy. Nat Genet. 2010;42:786-789. 
85. Miyagawa T, Toyoda H, Hirataka A, et al. New susceptibility variants to narcolepsy identified in HLA class II region. Hum Mol Genet. 2015;24:891-898.

86. Han F, Lin L, Schormair B, et al. HLA DQB1*06:02 negative narcolepsy with hypocretin/orexin deficiency. Sleep. 2014;37:1601-1608.

87. Tafti M, Hor H, Dauvilliers Y, et al. DQB1 locus alone explains most of the risk and protection in narcolepsy with cataplexy in Europe. Sleep. 2014;37:19-25.

88. Weiner-Lachmi K, Lin L, Kornum BR, et al. DQB1*06:02 allelespecific expression varies by allelic dosage, not narcolepsy status. Hum Immunol. 2012;73:405-410.

89. Cvetkovic-Lopes V, Bayer L, Dorsaz S, et al. Elevated Tribbles homolog 2-specific antibody levels in narcolepsy patients. J Clin Invest. 2010;120:713-719.

90. Kawashima M, Lin L, Tanaka S, et al. Anti-Tribbles homolog 2 autoantibodies in narcolepsy are associated with recent onset of cataplexy. Sleep. 2010;33:869-874.

91. Dauvilliers Y, Montplaisir J, Cochen V, et al. Post-H1N1 narcolepsycataplexy. Sleep. 2010;33:1428-1430.

92. Chemelli RM, Willie JT, Sinton CM, et al. Narcolepsy in orexin knockout mice: molecular genetics of sleep regulation. Cell. 1999;98:437-451.

93. Lin L, Faraco J, Li R, et al. The sleep disorder canine narcolepsy is caused by a mutation in the hypocretin (orexin) receptor 2 gene. Cell. 1999;98:365-376.

94. Peyron C, Faraco J, Rogers W, et al. A mutation in a case of early onset narcolepsy and a generalized absence of hypocretin peptides in human narcoleptic brains. Nat Med. 2000;6:991-997.

95. Thannickal TC, Moore RY, Nienhuis R, et al. Reduced number of hypocretin neurons in human narcolepsy. Neuron. 2000;27:469-474.

96. Chabas D, Taheri S, Renier C, Mignot E. The genetics of narcolepsy. Annu Rev Genomics Hum. 2003;4:459-483.

97. Mignot EJ. History of narcolepsy at Stanford University. Immunol Res. 2014;58:315-339.

98. Miyagawa T, Kawashima M, Nishida N, et al. Variant between CPT1B and $\mathrm{CHKB}$ associated with susceptibility to narcolepsy. Nat Genet. 2008;40:1324-1328.

99. Miyagawa T, Honda M, Kawashima M, et al. Polymorphism located between CPT1B and CHKB, and HLA-DRB1*1501-DQB1*0602 haplotype confer susceptibility to CNS hypersomnias. PLoS One. 2009; 4:e5394.

100. Miyagawa T, Miyadera H, Tanaka S, et al. Abnormally low serum acylcarnitine levels in narcolepsy patients. Sleep. 2011;34:349A-353A.

101. Miyagawa T, Kawamura H, Obuchi M, et al. Effects of oral L-carnitine administration in narcolepsy patients: a randomized, double-blind, cross-over and placebo-controlled trial. PLoS One. 2013;8:e53707.
102. Khor SS, Miyagawa T, Toyoda H, et al. Genome-wide association study of HLA-DQB1*06:02 negative essential hypersomnia. Peer J. 2013;1:e66.

103. Hallmayer J, Faraco J, Lin L, et al. Narcolepsy is strongly associated with the T-cell receptor alpha locus. Nat Genet. 2009;41:708-711.

104. Miyagawa T, Honda M, Kawashima M, et al. Polymorphism located in TCRA locus confers susceptibility to essential hypersomnia with HLA-DRB1*1501-DQB1*0602 haplotype. J Hum Genet. 2010; 55:63-65.

105. Kornum BR, Kawashima M, Faraco J, et al. Common variants in P2RY11 are associated with narcolepsy. Nat Genet. 2011;43:66-71.

106. Han F, Lin L, Li J, et al. TCRA, P2RY11, and CPT1B/CHKB associations in Chinese narcolepsy. Sleep Med. 2012;13:269-272.

107. Faraco J, Lin L, Kornum BR, et al. ImmunoChip study implicates antigen presentation to T cells in narcolepsy. PLoS Genet. 2013; 9:e1003270.

108. Han F, Faraco J, Dong XS, et al. Genome wide analysis of narcolepsy in China implicates novel immune loci and reveals changes in association prior to versus after the $2009 \mathrm{H} 1 \mathrm{~N} 1$ influenza pandemic. PLoS Genet. 2013;9:e1003880.

109. Yamasaki M, Miyagawa T, Toyoda H, et al. Genome-wide analysis of $\mathrm{CNV}$ and their associations with narcolepsy in a Japanese population. J Hum Genet. 2014;59:235-240.

110. Luca G, Haba-Rubio J, Dauvilliers Y, et al. Clinical, polysomnographic and genome-wide association analyses of narcolepsy with cataplexy. J Sleep Res. 2013;22:482-495.

111. Manolio TA, Collins FS, Cox NJ, et al. Finding the missing heritability of complex diseases. Nature. 2009;461:747-753.

112. Maurano MT, Humbert R, Rynes E, et al. Systematic localization of common disease-associated variation in regulatory DNA. Science. 2012;337:1190-1195.

113. Pharoah PD, Tsai YY, Ramus SJ, et al. GWAS meta-analysis and replication identifies three new susceptibility loci for ovarian cancer. Nat Genet. 2013;45:362-370.

114. Subramanian A, Tamayo P, Mootha VK, et al. Gene set enrichment analysis: a knowledge-based approach for interpreting genomewide expression profiles. Proc Natl Acad Sci U S A. 2005;102: $15545-15550$.

115. Gene Ontology Consortium. Gene Ontology Consortium: going forward. Nucleic Acids Res. 2015;43:D1049-D1056.

116. Network and Pathway Analysis Subgroup of Psychiatric Genomics Consortium. Psychiatric genome-wide association study analyses implicate neuronal, immune and histone pathways. Nat Neurosci. 2015;18:199-209.
Advances in Genomics and Genetics

\section{Publish your work in this journal}

Advances in Genomics and Genetics is an international, peer reviewed, open access journal that focuses on new developments in characterizing the human and animal genome and specific gene expressions in health and disease. Particular emphasis will be given to those studies that elucidate genes, biomarkers and targets in the development of new or improved therapeutic

\section{Dovepress}

interventions. The journal is characterized by the rapid reporting of reviews, original research, methodologies, technologies and analytics in this subject area. The manuscript management system is completely online and includes a very quick and fair peer-review system. Visit http://www.dovepress.com/ testimonials.php to read real quotes from published authors. 